\title{
EXPERIMENTAL CHARACTERIZATION OF THE FLEXURAL BEHAVIOUR OF STEEL FIBRE REINFORCED CONCRETE ACCORDING TO RILEM TC 162-TDF RECOMMENDATIONS
}

Joaquim Barros and Joaquim Antunes

University of Minho, Portugal

\begin{abstract}
The post-cracking energy absorption capacity is the concrete property most benefited by steel fibre reinforcement, usually designated by toughness. Different test set-ups, test procedures and parameters have been proposed to evaluate the toughness of the steel fibre reinforced concrete (SFRC), but none of them has received a general acceptation by scientific and technical communities. As a consequence, designers put some reserves on the use of SFRC, because they are not confident on the design practice to be adopted, resulting in the exclusion of SFRC in applications where it could be the most suitable solution. In the last years RILEM TC 162 - TDF has published documents where recommendations for characterizing and designing SFRC structures are proposed. A general acceptation of these recommendations can be only taken if they are deeply analysed and checked by a large number of research centres.

This work intends to give some contribution for this analysis. It has also the purpose of evaluating the influence of the fibre content, percentage of cement replaced by fly ash and SFRC age on the post-cracking behaviour of the SFRC, under the experimental framework recommended by RILEM TC 162 - TDF.
\end{abstract}

\section{Introduction}

Steel fibre reinforced concrete (SFRC) is a cement-based material reinforced with discrete steel fibres randomly distributed. In shotcrete applications, like tunnelling, the fibres can get some preferential orientation. In plain concrete specimens submitted to uni-axial tensile stable tests, after peak load the stress is gradually decreasing with the increase of the deformation, the so-called "strain-softening" [1]. The area under the stress-crack opening relationship that can be obtained from this type of test is the 
fracture energy [2], a measure that represents the material energy absorption capacity during its fracture process. The fracture energy, the shape of the softening branch, and the uni-axial tensile strength are the fracture parameters adopted in some numerical models in the simulation of the post-cracking behaviour [2,3].

The energy dissipated in concrete cracking is the property most benefited by fibre reinforcement mechanisms, but the concept of fracture energy is not well applicable to SFRC because, for content of fibres used in current applications, and for crack width limits adopted in the design practice, this material sustains high residual stress values, i.e., the energy dissipated up to these crack width limits can be a small part of the total energy [4]. Therefore, some authors and institutions have proposed different parameters and procedures to characterize the energy dissipated in the fracturing process of the SFRC, usually designated by fracture toughness [5-9]. In these methodologies, different types of specimens, experimental set-ups, test procedures, and fracture toughness parameters are used, being too difficult the correlation amongst the results obtained. This leads to considerable restrictions in the use of SFRC, even in the applications where it would be adequate, because the designers are not confident in the methodology to adopt for characterizing and designing a given SFRC. Beside this fact, it was verified that the major part of the toughness parameters only gives an idea of the energy absorption capacity of the SFRC, but was not introduced in the formulations proposed by the model codes. Therefore, the designer has a qualitative evaluation of the SFRC fracture toughness but faces difficulties in using this information.

With the purpose of establishing standard procedures to test and design SFRC, RILEM TC 162-TDF published four documents. In the first one [10], recommendations for the experimental characterization of the bending behaviour of SFRC were proposed, as well as, equivalent flexural tensile strength parameters, $f_{\text {eq }}$, to represent the post-cracking energy absorption capacity. The second one [11] was dedicated to design SFRC structures using the concept of $f_{\text {eq }}$, under the framework of the European pre-standard ENV 1992-1-1 [12]. In 2001 a third paper [13] was published dealing with the recommendations for characterizing SFRC using uni-axial tensile tests. In the last publication [14] the concepts of the non-linear fracture mechanics [15] were used to provide recommendations for the design of SFRC structures. In a next publication [16] of the RILEM TC 162-TDF, the concept of residual flexural tensile strength, $f_{R}$, will be proposed, which gives the stress for different deflections or crack mouth opening displacements (CMOD). While $f_{e q}$ parameters are directly dependent on the energy dissipated up to given deflection (or CMOD), $f_{R}$ parameters give information about the shape of the post-peak load-deflection relationship.

In the present work, the flexural behaviour of concrete reinforced with two types of hooked ends steel fibres was characterized according to the RILEM TC 162-TDF recommendations. The influence of the content of fibres (Cf), percentage of cement replaced by fly ash $(\mathrm{Fa})$, and age $(\mathrm{Ag})$ of SFRC was analysed under the point of view of the load-deflection response (F- $\delta$ ), and the values of the $f_{e q}$ parameters. The distribution 
of the steel fibres on the fracture surface of the specimens tested was also evaluated for estimating its dependence on the mix workability, and its influence on the $\mathrm{F}-\delta$ relationship and $f_{e q}$ values. The values of the equivalent and residual flexural tensile strength parameters obtained in the campaign of tests carried out were correlated.

\section{RILEM TC 162-TDF recommendations for SFRC}

Figure 1 represents the specimen recommended by RILEM TC 162-TDF for the characterization of the flexural behaviour of SFRC [10]. The method for casting the specimens, the curing procedures, the position and dimensions of the notch sawn into the specimen, the loading and specimen support conditions, the characteristics for both the equipment and measuring devices, and the test procedures are given elsewhere [10].

From a bending test a force-deflection relationship, F- $\delta$, is obtained. If a clip-gauge is mounted on the mouth of the notch, a force-crack mouth opening displacement relationship, F-CMOD, can also be registered. From these relationships the load at the limit of proportionality $\left(\mathrm{F}_{\mathrm{L}}\right)$, and the equivalent $\left(f_{\text {eq, } 2}\right.$ and $\left.f_{\text {eq, } 3}\right)$ and the residual $\left(f_{R, 1}\right.$ and $f_{R, 4}$ ) flexural tensile strength parameters can be evaluated. $\mathrm{F}_{\mathrm{L}}$ is equal to the highest value of the load registered up to a deflection (or CMOD) of $0.05 \mathrm{~mm}$. The parameters $f_{\text {eq, } 2}$ and $f_{\text {eq, } 3}$ are related to the material energy absorption capacity up to a deflection of $\delta_{2}$ and $\delta_{3}$ $\left(\delta_{2}=\delta_{\mathrm{L}}+0.65 \mathrm{~mm}\right.$ and $\delta_{3}=\delta_{\mathrm{L}}+2.65 \mathrm{~mm}$, where $\delta_{\mathrm{L}}$ is the deflection corresponding to $\mathrm{F}_{\mathrm{L}}$ ) provided by fibre reinforcement mechanisms, $\left(D_{B Z, 2}^{f}\right.$ and $D_{B Z, 3}^{f}$ ), see Figure 2 and Figure 3. The parcel of the energy due to the fracture of plain concrete $\left(D_{B Z}^{b}\right)$ was not considered on the $f_{e q}$ evaluation. The parameters $f_{R, I}$ and $f_{R, 4}$ are the stresses due to forces $F_{R, 1}$ and $F_{R, 4}$, respectively, corresponding to a deflection of $\delta_{\mathrm{R}, 1}=0.46 \mathrm{~mm}$ and $\delta_{\mathrm{R}, 4}=3.0 \mathrm{~mm}$ (see Figure 2 and Figure 3 ). The expressions for evaluating $f_{\text {eq }}$ and $f_{R}$ are inset of Figures 2 and 3, where $b(=150 \mathrm{~mm})$ and $L(=500 \mathrm{~mm})$ are the width and the span of the specimen, and $h_{s p}$ $(=125 \mathrm{~mm})$ is the distance between the tip of the notch and the top of the cross section. All these expressions were defined assuming a linear stress distribution on the cross section. According to RILEM TC 162-TDF $[11,16], f_{e q, 2}$ or $f_{R, 1}$ is used in the verifications of the serviceability limit states while $f_{e q, 3}$ or $f_{R, 4}$ is taken in the ultimate limit states, under the framework of the European pre-standard ENV 1992-1-12 [12].
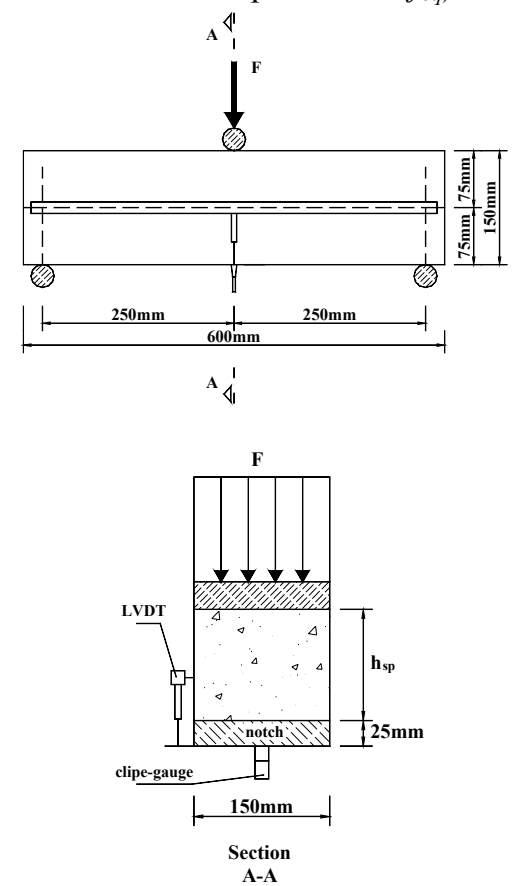

Figure 1 - Specimen dimensions, arrangement of the displacement transducers and loading conditions 


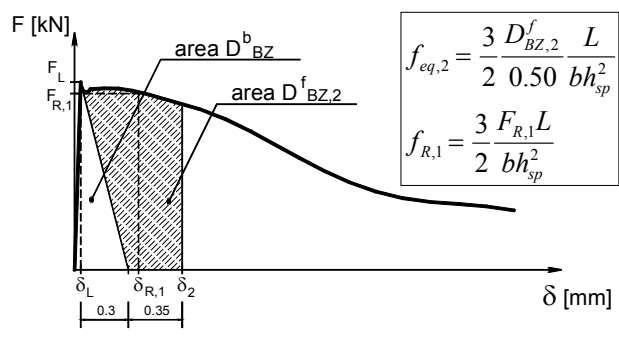

Figure 2 - Evaluation of the equivalent two $\left(f_{e q, 2}\right)$ and residual one $\left(f_{R, 1}\right)$ flexural tensile strength parameters.

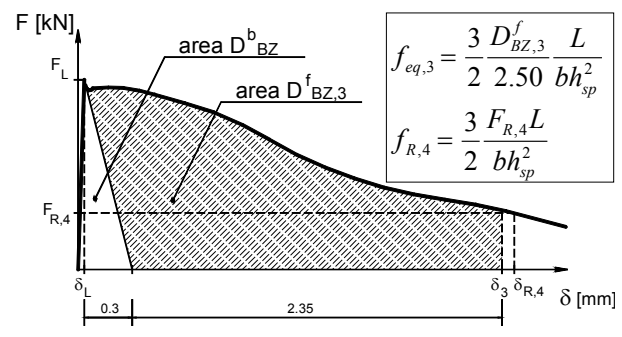

Figure 3 - Evaluation of the equivalent three $\left(f_{e q, 3}\right)$ and residual four $\left(f_{R, 4}\right)$ flexural tensile strength parameters.

\section{Materials, manufacturing and curing procedures}

It was designed SFRC compositions to accomplish the following conditions: average compression strength greater than $25 \mathrm{MPa}$ at 28 days; content of binding (cement + fly ash) equal to $300 \mathrm{~kg} / \mathrm{m}^{3}$; slump greater than $15 \mathrm{~cm}$; use of available aggregates in the North Region of Portugal. The SFRC designed has the strength and the workability adjusted for being used in structural applications, such as: partial replacement of conventional reinforcement by steel fibres (hybrid reinforcement); slabs on grade.

Two types of hooked ends DRAMIX ${ }^{\circledR}$ steel fibres were used: RC-80/60-BN with a length $\left(l_{f}\right)$ of $60 \mathrm{~mm}$, a diameter $\left(d_{f}\right)$ of $0.75 \mathrm{~mm}$, an aspect-ratio $\left(l_{f} / d_{f}\right)$ of 80 ; RC-65/60-BN with $l_{f}=60 \mathrm{~mm}, d_{f}=0.92 \mathrm{~mm}$ and $l_{f} / d_{f}=65$. Both fibres have a yield stress of about $1100 \mathrm{MPa}$. The compositions are included on Table 1. With the aim of obtaining similar compression strength and mix workability in all compositions, the water/binding (w/b) ratio was decreased with the increase of fly ash. Table 2 reveals that this purpose was practically attained. The influence of the fly ash was only appreciable in specimens with 7 days.

The manufacturing and the curing procedures of the specimens were the ones recommended by RILEM TC 162-TDF [10].

Table 1 - Compositions

\begin{tabular}{l|c|c|c}
\hline \multicolumn{1}{c|}{ Component } & \multicolumn{3}{c}{ Content $\left[\mathrm{kg} / \mathbf{m}^{3}\right]$} \\
\hline Cement I 42.5R & 300.0 & 262.5 & 225.0 \\
\hline Fly Ash (\% of cement) & $0.0(0.0)$ & $37.5(12.5)$ & $75.0(25.0)$ \\
\hline Fine sand & 173.5 & 165.5 & 152.3 \\
\hline Crushed sand & 871.0 & 875.5 & 869.1 \\
\hline $5 / 15$ coarse aggregate & 315.7 & 319.1 & 319.1 \\
\hline $15 / 25$ coarse aggregate & 468.2 & 470.6 & 467.0 \\
\hline Water & 163.8 & 158.8 & 153.8 \\
\hline Superplasticizer (Rheobuild $\left.{ }^{\circledR} 1000\right)$ & \multicolumn{3}{|c}{0.7 .5} \\
\hline \multirow{2}{*}{ Steel fibres (\% in volume) } & $80 / 60$ & $65 / 60$ & $15(0.19) ; 25(0.32) ; 35(0.45) ; 45(0.57)$ \\
\cline { 2 - 5 }
\end{tabular}

BARROS, Flexural experimental characterization, $4 / 4$

Fax: (+351) 253510217

E-mail: barros@civil.uminho.pt 
Table 2 - Compression strength (evaluated on cubes of $150 \mathrm{~mm}$ edge)

\begin{tabular}{c|c|c}
\hline Age [days] & Fly-ash [\%] & $\mathbf{f}_{\mathbf{c m}}[\mathbf{M P a}]$ \\
\hline \multirow{3}{*}{7} & 0.0 & 37.0 \\
\cline { 2 - 3 } & 12.5 & 30.1 \\
\cline { 2 - 3 } & 25.0 & 26.5 \\
\hline \multirow{3}{*}{28} & 0.0 & 39.7 \\
\cline { 2 - 3 } & 12.5 & 39.3 \\
\cline { 2 - 3 } & 25.0 & 34.8 \\
\hline \multirow{3}{*}{90} & 0.0 & 47.2 \\
\cline { 2 - 3 } & 12.5 & 46.6 \\
\cline { 2 - 3 } & 25.0 & 45.5 \\
\hline
\end{tabular}

\section{Fibre distribution on the fracture surface}

Apart very specific applications, RILEM TC 162-TDF [10] recommends that the loading direction should be orthogonal to the casting direction. The SFRC designed in the present work has high workability, which can induce significant fibre segregation during the compaction procedure. To evaluate the degree of the fibre segregation, the specimen's fracture surface was discretized in four rows and five columns of cells, as it is represented in Figure 4. The average number of fibres counted (visible on the fracture surface) is represented in Figure 5, where an increase of the fibre percentage in the casting direction was observed $[17,18]$. This fibre segregation was more pronounced on specimens reinforced with fibres $80 / 60$, and has promoted the development of nonuniform crack opening, as it is shown in Figure 6. Due to the lower percentage of fibres on the top surface in the casting direction, the crack in this surface developed more quickly than on the bottom surface. Therefore, for SFRC of high workability, placed with some vibration, fibre segregation has high probability to occur. In this case, the post cracking behaviour of the SFRC specimen is largely dependent on the loading direction, which should simulate the loading of the real application, as much as possible.

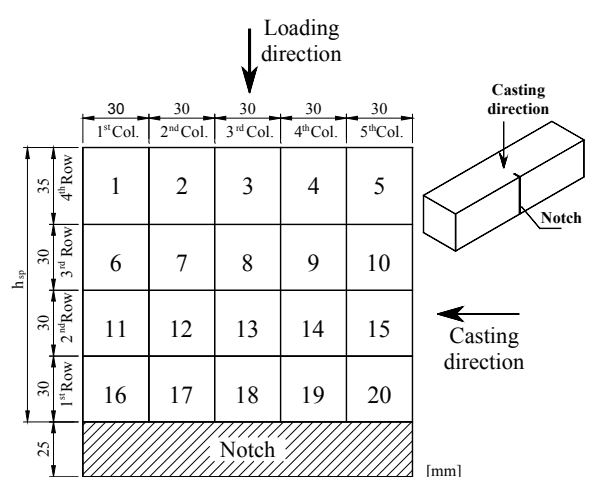

Figure 4 - Discretization in cells of the specimen's fracture surface.

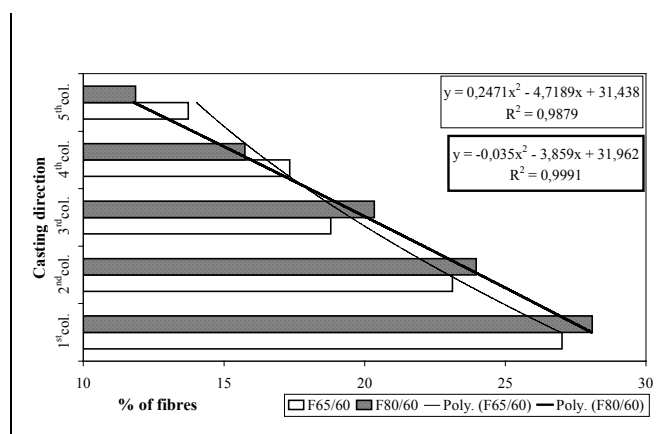

Figure 5 - Average fibre distribution. 
Figure 7 presents the relationship between the content of fibres and the number of fibres counted on the fracture surface of the specimens tested. As it was expected, the number of fibres on the fracture surface increased with the content of fibres. For fibres $80 / 60$, in general, the increase was larger between 20 and $30 \mathrm{~kg} / \mathrm{m}^{3}$, while for fibres $65 / 60$ the largest increase occurred between 35 and $45 \mathrm{~kg} / \mathrm{m}^{3}$ of fibres. Above $20 \mathrm{~kg} / \mathrm{m}^{3}$ of fibres, the increase of the number of fibres on the fracture surface, in general, was greater on fibres $80 / 60$ than on fibres $65 / 60$. The smallest increase of the number of fibres on the fracture surface of specimens reinforced with fibres $65 / 60$ occurred
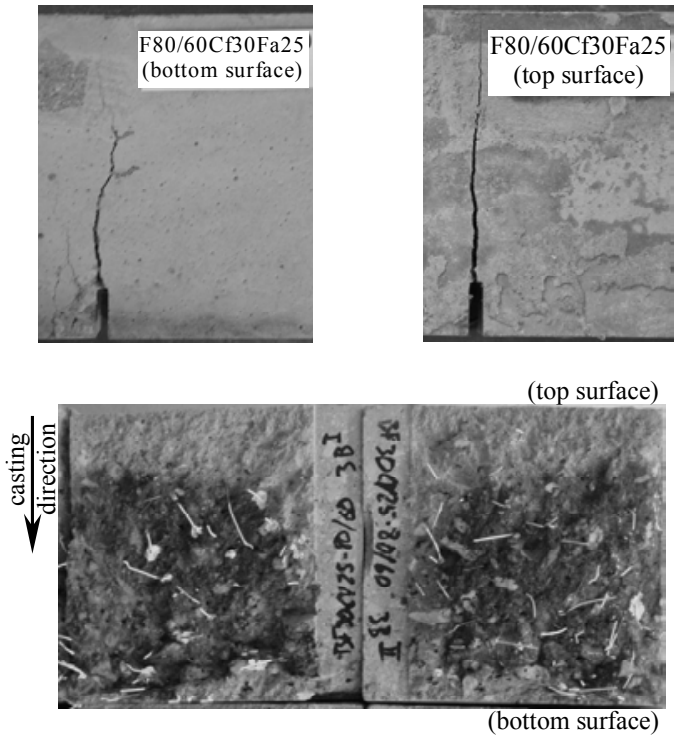

Figure 6 - Non-uniform crack opening due to fibre segregation.

a)
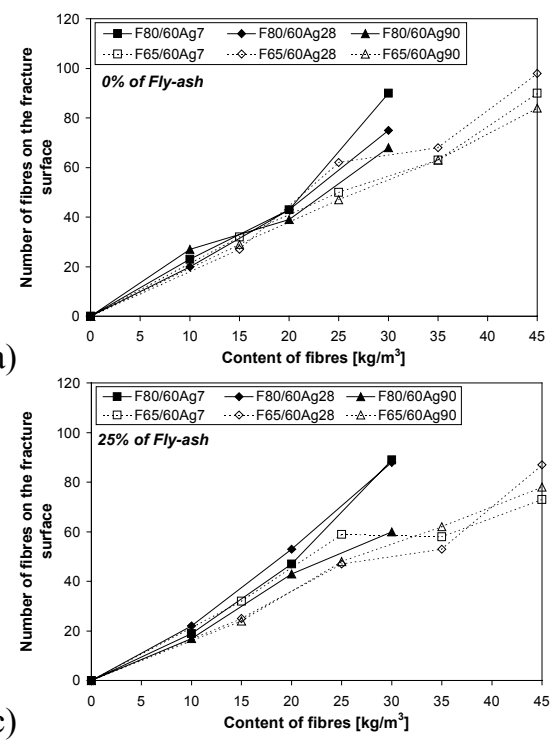

b)

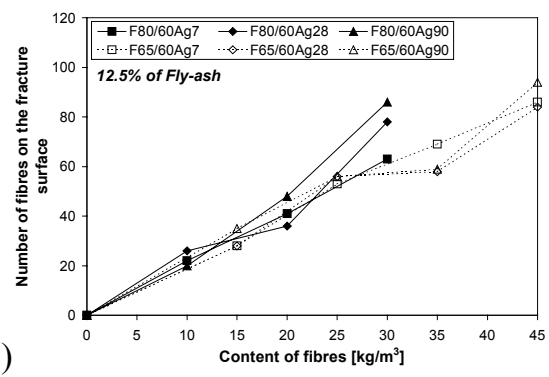

Figure 7 - Relationship between the content and the number of fibres on the fracture surface: a) $0 \%$, b) $12.5 \%$, c) $25 \%$ of cement replaced by Fa.

BARROS, Flexural experimental characterization, 6/6

Fax: (+351) 253510217

E-mail: barros@civil.uminho.pt 


\section{Flexural behaviour}

\subsection{Introduction}

In this section, the results obtained on the bending tests carried out are presented in a format adjusted for showing, mainly, the influence of the fibre content, the percentage of cement replaced by fly ash and the age of concrete specimens.

\subsection{Force-deflection relationship}

Figure 8 includes the F- $\delta$ relationships registered on specimens with 28 days. Due to the lack of space, the F- $\delta$ relationships of specimens with 7 and 90 days are not included, but the general trends observed in specimens with 28 days can be also applied to specimens of the other ages.

A generic series has the designation of $\mathrm{F} \alpha \alpha / \beta \beta \mathrm{Cf} \gamma \gamma$, where $\mathrm{F}$ and $\mathrm{Cf}$ mean fibre and content of fibres, respectively, $\alpha \alpha / \beta \beta$ represents the fibre type $(80 / 60$ or $65 / 60)$ and $\gamma \gamma$ is the $\mathrm{Cf}$ in $\mathrm{kg} / \mathrm{m}^{3}$ of concrete. In the graphs it appears also the acronym $\operatorname{Fa} \eta \eta \operatorname{Ag} \lambda \lambda$, where $\mathrm{Fa}$ and $\mathrm{Ag}$ mean fly ash and age, respectively, $\eta \eta$ the percentage of cement replaced by $\mathrm{Fa}$ and $\lambda \lambda$ the specimen age, in days, when tested.

Each curve is the average relationship of three specimens. A generic $\mathrm{F}-\delta$ relationship is characterized by a linear branch up to a point near the peak load. After peak load, a load decay was occurred, with an amplitude that is so high as less is the number of fibres on the fracture surface, mainly on the first row of cells discretizing the fracture surface (see Figure 4).

In some $\mathrm{F}-\delta$ relationships, after peak load it occurred a "hardening" branch, i.e., the load increased with the deflection.

From the analysis of the F- $\delta$ relationships of Figure 8 it was verified that:

- some series have shown residual resistance (load bearing capacity after peak load) similar or even higher the one
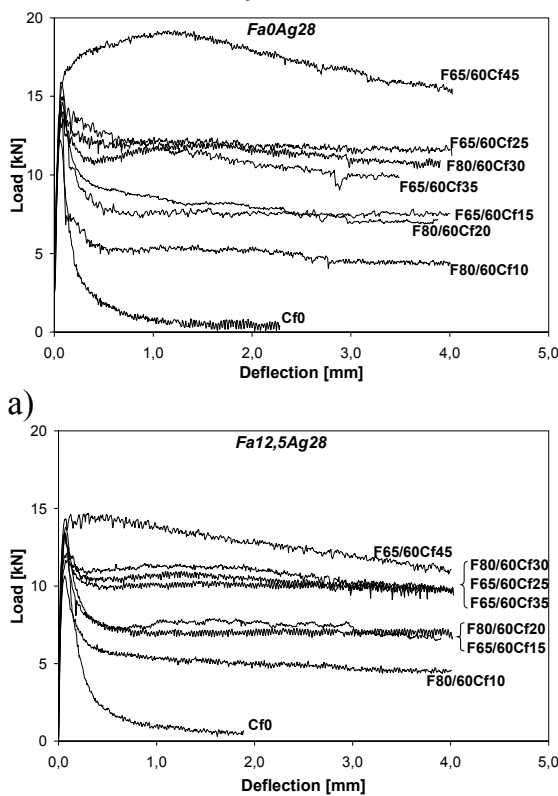

b)

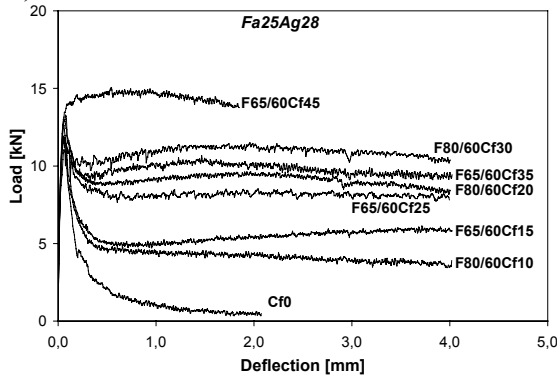
c)

Figure 8 - Load-deflection relationship of specimens with 28 days: a) $0 \%$, b) $12.5 \%$, c) $25 \%$ of $\mathrm{Fa}$. 
registered on series with higher number of fibres on the fracture surface. For instance, series $\mathrm{F} 65 / 60 \mathrm{Cf} 15 \mathrm{Fa} 0$ and $\mathrm{F} 80 / 60 \mathrm{Cf} 20 \mathrm{Fa} 0$ developed similar residual resistance, in spite of series $\mathrm{F} 80 / 60 \mathrm{Cf} 20 \mathrm{Fa} 0$ has had higher number of fibres on the fracture surface (43) than series F65/60Cf15Fa0 (27). Similar situation occurred between series F65/60Cf15Fa12.5 (28 fibres) and F80/60Cf20Fa12.5 (36 fibres), as well as, between series F65/60Cf25Fa12.5 (56 fibres) and F80/60Cf30Fa12.5 (75 fibres);

- series F65/60Cf45 developed the largest residual resistance amongst the series tested, because the number of fibres on the fracture surface of the specimens of these series was significantly larger.

From the F- $\delta$ relationships of the series without Fa it can be extracted the following observations:

- for a deflection larger than $1 \mathrm{~mm}$, series $\mathrm{F} 65 / 60 \mathrm{Cf} 25$ presented a residual resistance larger than the one of series F65/60Cf35. This unexpected behaviour can be justified by the larger percentage of fibres on the second and third rows of the fracture surface (see Figure 4) of series F65/60Cf25. However, between the deflection corresponding to peak load and $1 \mathrm{~mm}$, series F65/60Cf35 shown a larger residual resistance, because it had larger percentage of fibres on the first row of the fracture surface. These two series have developed a behaviour similar to the one of series F80/60Cf30, because the number of fibres on the fracture surface was similar (between 62 and 72 fibres);

- in the post-cracking of series $\mathrm{F} 65 / 60 \mathrm{Cf} 45$, the load increased up to a deflection of about $1.2 \mathrm{~mm}$ ("hardening" branch), because the largest percentage of fibres was concentrated on the first row of the fracture surface.

From the F- $\delta$ relationships of the series with $12.5 \%$ of cement replaced by Fa it was verified that series F65/60Cf25 and F65/60Cf35 had similar behaviour because the number of fibres on the fracture surface was about the same (56 and 58 , respectively).

From the F- $\delta$ relationships of the series with $25 \%$ of cement replaced by $\mathrm{Fa}$ it was verified that the toughness was proportional to the number of fibres on the fracture surface $\quad(F 80 / 60 C f 10=21, \quad F 65 / 60 C f 15=25, \quad F 65 / 60 C f 25=47, \quad F 80 / 60 C f 20=51$, $\mathrm{F} 65 / 60 \mathrm{Cf} 35=53, \mathrm{~F} 80 / 60 \mathrm{Cf} 30=84, \mathrm{~F} 65 / 60 \mathrm{Cf} 45=87$ ). For a deflection larger than $1 \mathrm{~mm}$, series $\mathrm{F} 65 / 60 \mathrm{Cf} 15$ presented an increase in the residual resistance with the increase deflection, due to the fact that the percentage of fibres was larger in the last three rows of the fracture surface.

\subsection{Flexural tensile strength parameters}

Figure 9 reveals that equivalent flexural tensile strength parameters $\left(f_{\text {eq, } 2}\right.$ and $\left.f_{\text {eq, } 3}\right)$ have similar values, showing that, up to a deflection of $\delta_{3}$ the energy absorption capacity of the SFRC designed is linearly dependent on the deflection. Therefore, it is enough to analyse the evolution of the $f_{e q, 2}$, because the comments can be also applied to $f_{e q, 3}$.

5.3.1 Influence of the fibre content 
Figure 10 represents the evolution of the $f_{\text {eq, }}$ with the fibre content. It is verified that, for both types of fibres, $f_{e q, 2}$ has an almost linear relationship with the fibre content. A similar tendency was observed between the number of fibres on the fracture surface and the $f_{e q, 2}$, as it can be seen in Figure 11.

Between both type of fibres considered, the largest variation of $f_{e q, 2}$ with the fibre content occurred on series reinforced with content of fibres above $20 \mathrm{~kg} / \mathrm{m}^{3}$, with 7 days and without $\mathrm{Fa}$, which can be justified by the increase of the number of fibres on the fracture surface. Between 20 and $30 \mathrm{~kg} / \mathrm{m}^{3}$ of fibres 80/60 it was registered an increase of 49 fibres on the fracture surface, while the increase of the number of $65 / 60$ fibres on the fracture surface between 25 and $35 \mathrm{~kg} / \mathrm{m}^{3}$, and between 35 and $45 \mathrm{~kg} / \mathrm{m}^{3}$, was only 13 and 27 fibres, respectively.

For fibre 65/60, in general, the largest increase of $f_{e q, 2}$ occurred between 35 and $45 \mathrm{~kg} / \mathrm{m}^{3}$, mainly on specimens with 28 days, because the largest increase of the number of fibres on the fracture surface was observed amongst these series of specimens. Between 15 and $25 \mathrm{~kg} / \mathrm{m}^{3}$ of $65 / 60$ fibres, the increase of $f_{\text {eq, }}$ was also significant, and, in general, the magnitude of this increase followed the increase of the number of fibres on the fracture surface. Between 25 and $35 \mathrm{~kg} / \mathrm{m}^{3}$ of fibres $65 / 60$, in general, the increase of $f_{\text {eq, } 2}$ was not so pronounced as it was on the other two intervals, because the average increase of the number of fibres on the fracture surface for this interval was the smallest one, see Figure 7.

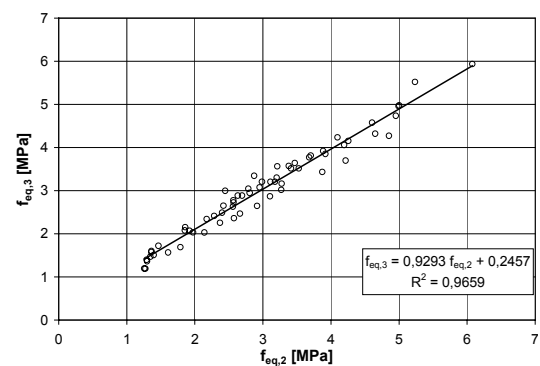

Figure 9 - Relationship between $f_{\text {eq, } 2}$ and $f_{e q, 3}$.
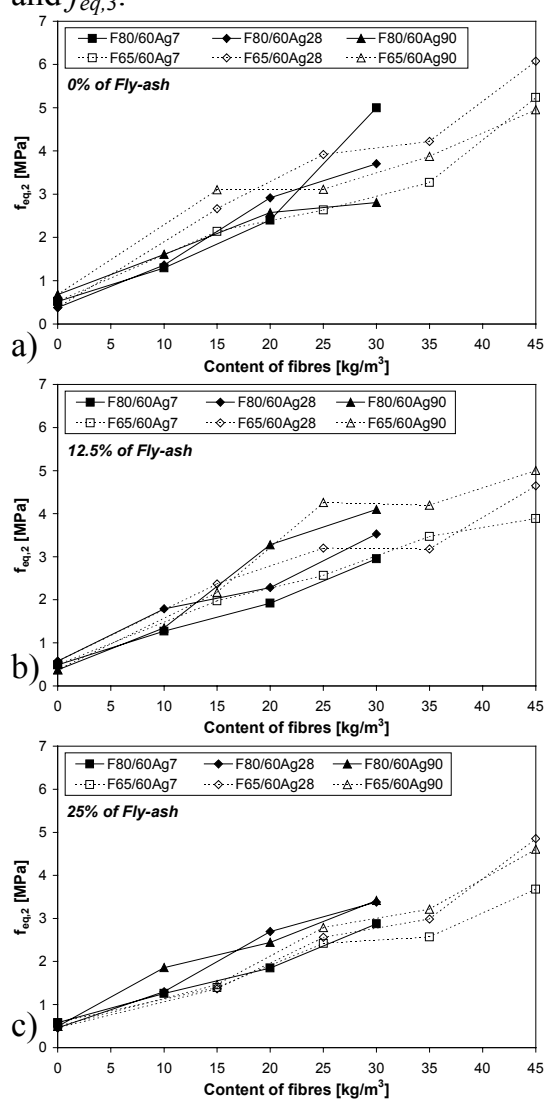

Figure 10 - Relationship between $f_{\text {eq, } 2}$ and Cf: a) $0 \%$, b) $12.5 \%$, c) $25 \%$ of Fa. 


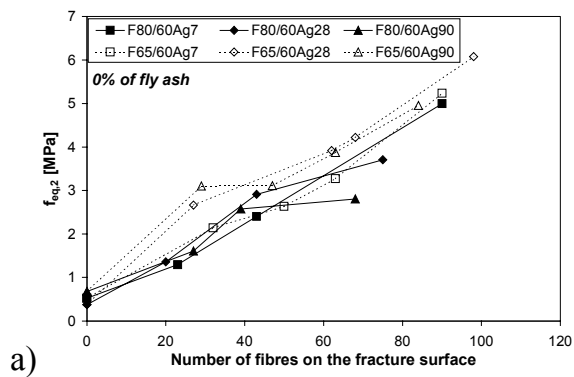

a)
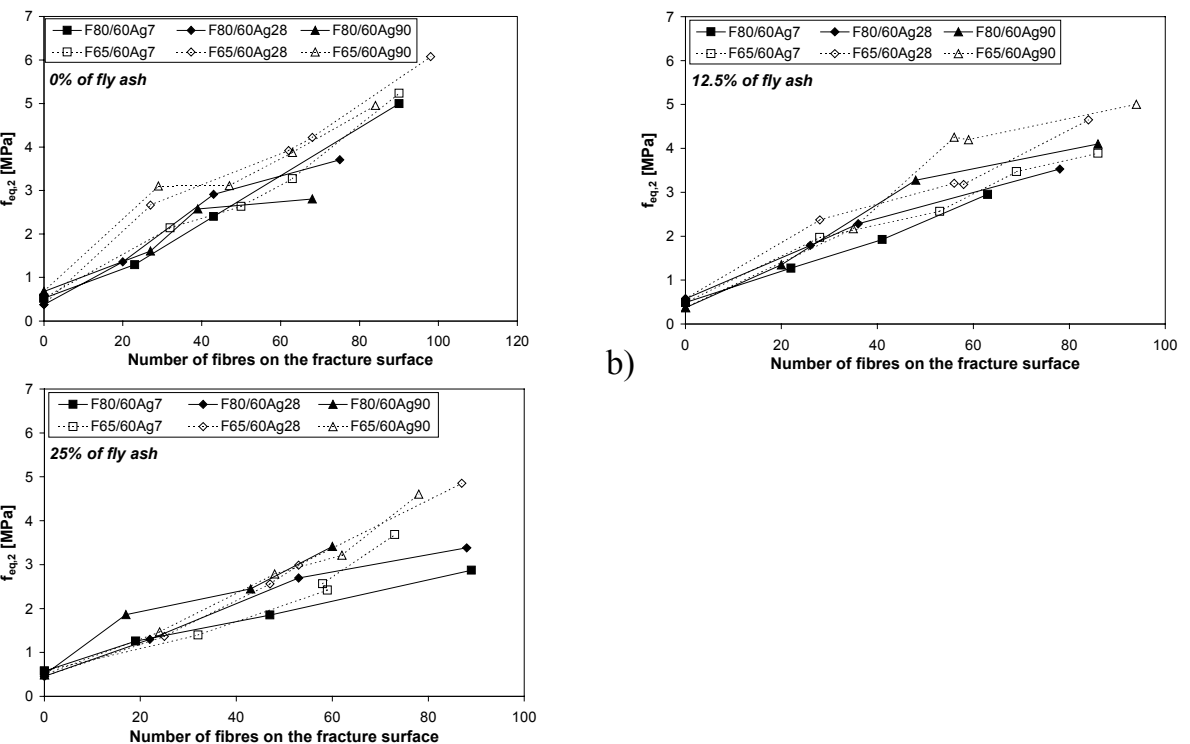

c)

Figure 11 - Relationship between $f_{\text {eq, } 2}$ and the number of fibres on the fracture surface: a) $0 \%, \mathrm{~b}) 12.5 \%$, c) $25 \%$ of Fa.

5.3.2 Influence of the percentage of cement replaced by fly ash

Figure 12 represents the evolution of the $f_{e q, 2}$ with the percentage of cement replaced by Fa. In general, it was observed a small decrease of the $f_{e q, 2}$ with the increase of the percentage of cement replaced by $\mathrm{Fa}$. This was achieved because the water/binding ratio was reduced when the percentage of cement replaced by Fa was increased, resulting concretes of similar compression strength, giving similar conditions for the mobilization of the fibre reinforcement mechanisms.

For fibre $80 / 60$ the influence of the percentage of cement replaced by Fa was only significant on the series reinforced with $30 \mathrm{~kg} / \mathrm{m}^{3}$ of fibres and with 7 days. Between series without $\mathrm{Fa}$ and $12.5 \%$ of $\mathrm{Fa}$, the verified decrease is justified by the difference of the number of fibres on the fracture surface ( 88 for $\mathrm{Fa}=0 \%$ and 61 for $\mathrm{Fa}=12.5 \%$ ). However, the difference between series with $\mathrm{Fa}=0 \%$ and $\mathrm{Fa}=25 \%$ cannot be justified by the number of fibres on the fracture surface, because both series had similar number $(87$ and 86). This difference is related to the concrete strength $(33.1 \mathrm{MPa}$ for $\mathrm{Fa}=0 \%$ and 19.7MPa for $\mathrm{Fa}=25 \%$ ). For SFRC with 7 days, the fibre reinforcement mechanisms are significantly influenced by the quality of the concrete matrix. Similar trend was observed on series reinforced with fibres $65 / 60$ and age of 7 days. In specimens with 90 days $f_{\text {eq, } 2}$ attained the maximum value in some series with $12.5 \%$ of $\mathrm{Fa}$, revealing that, at long curing period, the material energy absorption capacity is not significantly affected by the presence of Fa. Therefore, if live loads are applied when SFRC age is older than 90 days,

BARROS, Flexural experimental characterization, 10/10

Fax: (+351) 253510217

E-mail: barros@civil.uminho.pt 
some economy can be obtained in the SFRC costs, replacing cement by Fa, without reducing significantly the material energy absorption capacity.

a)
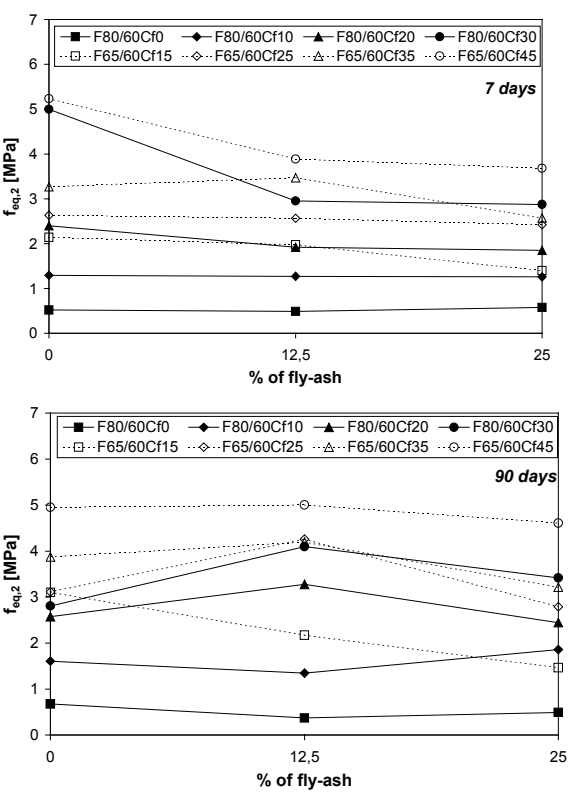

b)

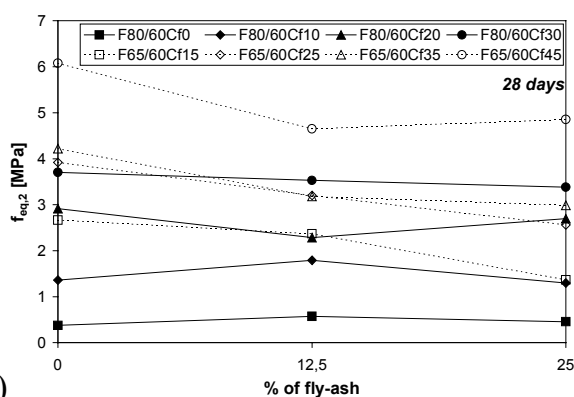

Figure 12 - Relationship between $f_{\text {eq, } 2}$ and percentage of cement replaced by Fa: a) 7 , b) 28 , c) 90 days.

\subsubsection{Influence of the age of concrete specimens}

Figure 13 represents the evolution of the $f_{\text {eq, } 2}$ with the age of the specimens. In general, it was observed an increase of the $f_{e q, 2}$ with the age of the specimens. This increase is more pronounced between 7 and 28 days, than between 28 and 90 days. In series reinforced with $45 \mathrm{~kg} / \mathrm{m}^{3}$ of $65 / 60$ fibres and without $\mathrm{Fa}$, a significant increase of $f_{\text {eq, } 2}$ occurred between 7 and 28 days, followed by a decrement between 28 and 90 days. This is justified by the number of fibres on the fracture surface $(90,98$ and 84 fibres for series with 7, 28 and 90 days, respectively). Similar behaviour happened on series reinforced with $45 \mathrm{~kg} / \mathrm{m}^{3}$ of $65 / 60$ fibres and with $25 \%$ of Fa, also justified by the number of fibres on the fracture surface $(73,87$ and 78 fibres for series with 7,28 and 90 days, respectively). In series reinforced with $30 \mathrm{~kg} / \mathrm{m}^{3}$ of $80 / 60$ fibres and without $\mathrm{Fa}, f_{\text {eq, }}$ decreased with the increase of specimen's age, which can be also justified by the number of fibres on the fracture surface $(87,72$ and 65 fibres for series with 7, 28 and 90 days, respectively). 

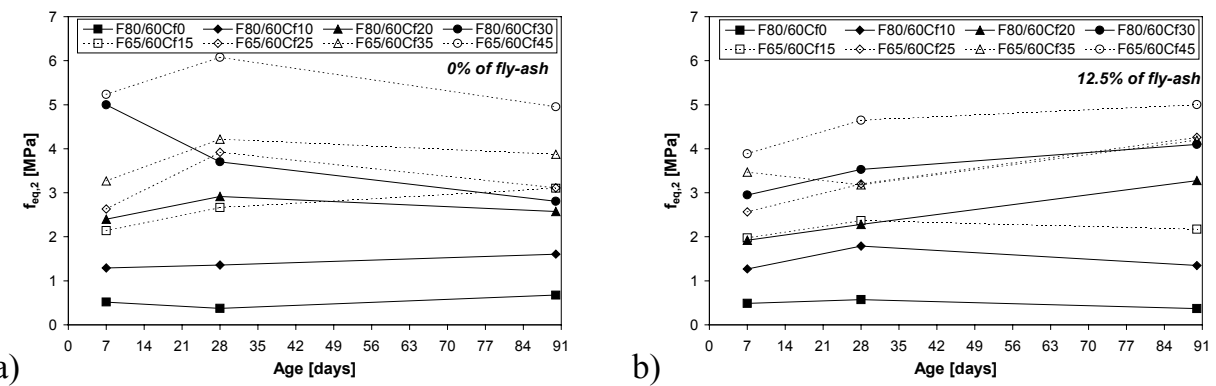

a)

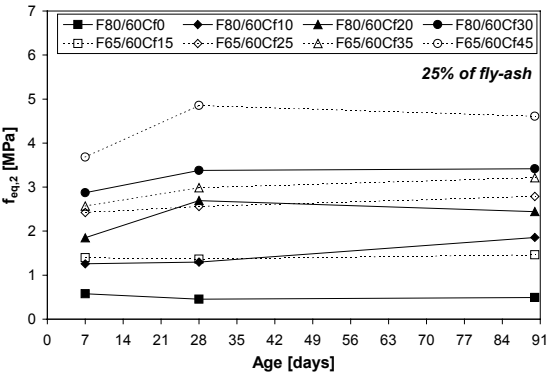

c)

b)

Figure 13 - Relationship between $f_{\text {eq, } 2}$ and the age of the concrete specimens: a) $0 \%$, b) $12.5 \%$, c) $25 \%$ of Fa.

\subsection{Equivalent versus residual flexural tensile strength parameters}

The relationships between $f_{e q, 2}$ and $f_{R, 1}$, and between $f_{e q, 3}$ and $f_{R, 4}$ are represented in Figure 14. It is observed a very good correlation between equivalent and residual flexural tensile strength parameters for both types of fibres. The correlation is better between $f_{\text {eq, } 2}$ and $f_{R, 1}$, than between $f_{e q, 3}$ e $f_{R, 4}$, because the contribution of the energy dissipated under large crack openings is more relevant for the latter one, which is a phase where the fibre length, fibre orientation and fibre-matrix bonding are governing factors on the post cracking behaviour.

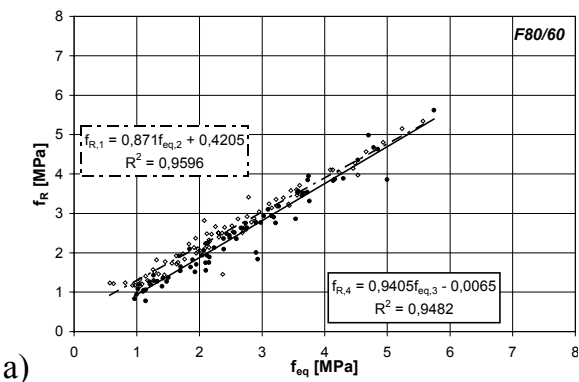

b)

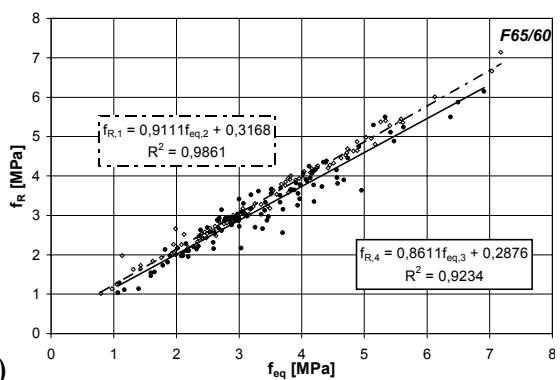

Figure 14 - Correlation between equivalent and residual flexural tensile strength parameters in a) $80 / 60$ and b) $65 / 60$ fibres.

BARROS, Flexural experimental characterization, 12/12

Fax: (+351) 253510217

E-mail: barros@civil.uminho.pt 


\section{Conclusions}

A cost competitive steel fibre reinforced concrete (SFRC) was designed with the strength and workability requirements for being used with conventional reinforcement (partial replacement of conventional reinforcement by steel fibres), or in flooring applications. To maintain similar values of compression strength and mix workability for the mixes designed, the water/cement ratio was decreased with the increase of the percentage of cement replaced by fly ash. Reduction on the costs of the SFRC was also verified to be possible with this replacement.

From the fibre distribution on the fracture surface of the SFRC specimens tested it was verified the occurrence of fibre segregation, that has promoted the development of nonuniform crack opening and has influenced the post-cracking behaviour of the SFRC specimens. Fibre segregation has high probability to occur on SFRC of high workability, placed with some vibration.

The post-cracking behaviour of the SFRC designed was assessed carrying out bending tests according to the recommendations of RILEM TC 162-TDF. The shape of the postpeak force-deflection relationship was deeply dependent on the number and distribution of the fibres on the specimen's fracture surface.

From the force-deflection relationship it was evaluated the equivalent $\left(f_{\text {eq, } 2}\right.$ and $\left.f_{\text {eq, } 3}\right)$ and residual $\left(f_{R, 1}\right.$ and $\left.f_{R, 4}\right)$ flexural tensile strength parameters. For the SFRC designed, similar values of $f_{e q, 2}$ and $f_{e q, 3}$ were obtained. It was also observed a good correlation between $f_{\text {eq, }}$ and $f_{R, 1}$, and between $f_{\text {eq,3 }}$ and $f_{R, 4}$.

The flexural tensile strength parameters have an almost linear increase with the fibre content, for both types of fibres considered. A detail examination has shown that the number of fibres on the specimen's fracture surface has conditioned this evolution.

Adopting the strategy of decreasing the water/binding ratio when the percentage of cement replaced by fly ash was increased, it was verified that, in general, the influence of the percentage of cement replaced by fly ash was not significant on the values of the flexural tensile strength parameters.

In general, it was observed an increase of the $f_{\text {eq, } 2}$ with the age of the specimens. This increase is more pronounced between 7 and 28 days, than between 28 and 90 days.

\section{Acknowledgements}

The study reported in this paper forms a part of the research program "Cost competitive steel fibre reinforced concrete for industrial pavements" supported by FCT, POCTI/34793/99. The aggregates were generously supplied by "Pisonort - Pavimentos industriais Lda", the cement by Secil, the superplasticizer by MBT, the fly ash by 
"Central do Pego" and the fibres by Bekaert NV. Special thanks for Civitest Lda due to lend some test equipment.

\section{References}

1. Hordijk, D.A. (1991), "Local approach to fatigue of concrete", PhD Thesis, Delft University of Technology.

2. Hillerborg, A.; Modéer, M.; Petersson, P.E. (1976), "Analysis of crack formation and crack growth in concrete by means of fracture mechanics and finite elements", Cement and Concrete Research, Vol. 6, pp. 773-782.

3. Barros, J.A.O., Figueiras, J.A. "Nonlinear analysis of steel fibre reinforced concrete slabs on grade", Computers \& Structures, Vol.79, No.1, pp. 97-106, January 2001.

4. Barragán, B.E., "Failure and toughness of steel fiber reinforced concrete under tension and shear", PhD Thesis, Technical University of Catalunya, Barcelona, Spain 2002.

5. "JSCE-SF4: method of tests for flexural strength and flexural toughness of steelfiber-reinforced concrete." (1984). Concrete library of JSCE. Japan Society of Civil Engineers (JSCE), Tokyo, Japan, Vol. 3, 58-61.

6. "ASTM C1018-89: standard test method for flexural toughness and first-crack strength of fiber-reinforced concrete (using beam with third-point loading)." (1991). Book of ASTM Standards: Part 04.02. ASTM, Philadelphia, Pa.

7. Gopalaratnam, V. S. et al. (1991). "Fracture toughness of fiber reinforced concrete." ACI Material Journal, 88(4) 339-353.

8. Chen, L., Mindess, S., Morgan, D. R. (1994). "Specimen geometry and toughness of steel-fiber-reinforced concrete." Journal of Materials in Civil Engineering, ASCE, 6(4), 529-541.

9. Trottier, J.-F., Banthia, N., "Toughness characterization of steel-fiber reinforced concrete", Journal of Materials in Civil Engineering, Vol. 6, No. 2, May 1994, pp. 264-289.

10. RILEM Technical Committee TDF-162 "Test and design methods for steel fiber reinforced concrete. Recommendations for bending test" (Chairlady L. Vandewalle), Mater. Struct. 33 (225, January-February 2000) 3-5.

11. RILEM Technical Committee TDF-162 "Test and design methods for steel fiber reinforced concrete. Recommendations for $\sigma-\varepsilon$ design method" (Chairlady L. Vandewalle), Mater. Struct. 33 (226, March 2000) 75-81.

12. ENV 1992-1-1. Eurocode 2: Design of concrete structures - Part 1: General rules and rules for buildings. Technical report, 1992. European pre-standard.

13. RILEM Technical Committee TDF-162 "Test and design methods for steel fiber reinforced concrete. Recommendations for uni-axial tension test" (Chairlady L. Vandewalle), Mater. Struct. 34 (235, January-February 2001) 3-6.

14. RILEM Technical Committee TDF-162 "Test and design methods for steel fiber reinforced concrete. Design of steel fibre reinforced using $\sigma-w$ method: principles and applications" (Chairlady L. Vandewalle), Mater. Struct. 35 (June 2002) 262278.

BARROS, Flexural experimental characterization, 14/14

Fax: (+351) 253510217

E-mail: barros@civil.uminho.pt 
15. Karihaloo, B.L., "Fracture Mechanics and Structural Concrete", Concrete Design and Construction Series, Longman Scientific \& Technical, Harlow, Essex, England, 1995.

16. RILEM Technical Committee TDF-162 "Test and design methods for steel fiber reinforced concrete. Final recommendation" (Chairlady L. Vandewalle), to be published on the Mater. Struct. Journal until the end of the 2002.

17. Barros, J.A.O., Antunes, J.A.B, Amorim, J.A.S.B.A., "Influência da quantidade de fibras, percentagem de cinzas volantes e idade no comportamento à flexão de betão reforçado com fibras de aço Dramix RC-80/60-BN", ("Influence of the fibre content, percentage of cement replaced by fly ash and concrete age on the behaviour of concrete reinforced with Dramix RC-80/60-BN steel fibres" Report 02-DEC/E-11, 87 pps., July 2002. (in Portuguese)

18. Antunes, J.A.B, Barros, J.A.O., Amorim, "Influência da quantidade de fibras, percentagem de cinzas volantes e idade no comportamento à flexão de betão reforçado com fibras de aço Dramix RC-65/60-BN", ("Influence of the fibre content, percentage of cement replaced by fly ash and concrete age on the behaviour of concrete reinforced with Dramix RC-65/60-BN steel fibres" Report 02-DEC/E-19, November 2002. (in Portuguese)

BARROS, Flexural experimental characterization, 15/15

Fax: (+351) 253510217

E-mail: barros@civil.uminho.pt 